
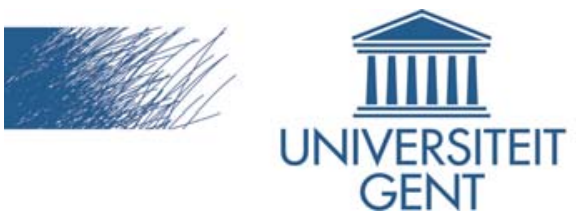

biblio.ugent.be

The UGent Institutional Repository is the electronic archiving and dissemination platform for all UGent research publications. Ghent University has implemented a mandate stipulating that all academic publications of UGent researchers should be deposited and archived in this repository. Except for items where current copyright restrictions apply, these papers are available in Open Access.

This item is the archived peer-reviewed author-version of: Modelling the primary drying step for the determination of the optimal dynamic heating pad temperature in a continuous pharmaceutical freeze-drying process for unit doses

Authors: De Meyer L., Lammens J., Mortier S., Vanbillemont B., Van Bockstal P.J., Corver J., Nopens I., Vervaet C., De Beer T.

In: International Journal of Pharmaceutics 2017, 532(1): 185-193

To refer to or to cite this work, please use the citation to the published version: Van De Meyer L., Lammens J., Mortier S., Vanbillemont B., Van Bockstal P.J., Corver J., Nopens I., Vervaet C., De Beer T. (2017) Modelling the primary drying step for the determination of the optimal dynamic heating pad temperature in a continuous pharmaceutical freeze-drying process for unit doses International Journal of Pharmaceutics 532(1): 185-193 DOI: 10.1016/j.ijpharm.2017.09.004 


\title{
Modelling the primary drying step for the determination of the optimal dynamic heating pad temperature in a continuous pharmaceutical freeze-drying process for unit doses
}

\author{
Laurens De Meyer ${ }^{\mathrm{a}}$, Joris Lammens ${ }^{\mathrm{c}}$, Séverine Thérèse F.C. Mortier ${ }^{\mathrm{b}, \mathrm{a}, 1}$, Brecht Vanbillemont $^{\mathrm{a}}$, Pieter Jan \\ Van Bockstal ${ }^{\mathrm{a}}$, Jos Corver ${ }^{\mathrm{a}}$, Ingmar Nopens ${ }^{\mathrm{b}}$, Chris Vervaet $^{\mathrm{c}}$, Thomas De Beer $^{\mathrm{a}, *}$ \\ ${ }^{a}$ Laboratory of Pharmaceutical Process Analytical Technology, Department of Pharmaceutical Analysis, Faculty of \\ Pharmaceutical Sciences, Ghent University, Ottergemsesteenweg 460, 9000 Ghent, Belgium \\ ${ }^{b}$ BIOMATH, Department of Mathematical Modelling, Statistics and Bioinformatics, Faculty of Bioscience Engineering, \\ Ghent University, Coupure Links 653, 9000 Ghent, Belgium \\ ${ }^{c}$ Laboratory of Pharmaceutical Technology, Department of Pharmaceutics, Department of Pharmaceutics, Faculty of \\ Pharmaceutical Sciences, Ghent University, Ottergemsesteenweg 460, 9000 Ghent, Belgium
}

\begin{abstract}
In the pharmaceutical industry, traditional freeze-drying of unit doses is a batch-wise process associated with many disadvantages. To overcome these disadvantages and to guarantee a uniform product quality and high process efficiency, a continuous freeze-drying process is developed and evaluated. The main differences between the proposed continuous freeze-drying process and traditional freeze-drying can be found firstly in the freezing step during which the vials are rotated around their longitudinal axis (spin freezing), and secondly in the drying step during which the energy for sublimation and desorption is provided through the vial wall by conduction via an electrical heating pad. To obtain a more efficient drying process, the energy transfer has to be optimised without exceeding the product and process limits (e.g. cake collapse, choked flow). Therefore, a mechanistic model describing primary drying during continuous lyophilisation of unit doses based on conduction via heating pads was developed allowing the prediction of the optimal dynamic power input and temperature output of the electric heating pads. The model was verified by experimentally testing the optimal dynamic primary drying conditions calculated for a model formulation. The primary drying endpoint of the model formulation was determined via in-line NIR spectroscopy. This endpoint was then compared with the predicted model based endpoint. The mean ratio between the experimental and model based predicted drying time for six verification runs was $1.05 \pm 0.07$, indicating a good accordance between the model and the experimental data.
\end{abstract}

Keywords: Continuous freeze-drying, Mathematical modelling, Conduction, NIR spectroscopy, Mechanistic modelling, Spin freezing

\section{Introduction}

In 2016, 50\% of the by the FDA's Center for Drug Evaluation and Research (CDER) approved novel drugs were biopharmaceuticals [1]. Many biopharmaceuticals are unstable in aqueous solution [2]. The fact

\footnotetext{
${ }^{*}$ Corresponding author

Email addresses: Laurens.DeMeyer@UGent.be (Laurens De Meyer), Joris.Lammens@UGent.be (Joris Lammens), Severine.Mortier@UGent.be (Séverine Thérèse F.C. Mortier), Brecht.Vanbillemont@UGent.be (Brecht Vanbillemont), pieterjan.vanbockstal@ugent.be (Pieter Jan Van Bockstal), Jos.Corver@RheaVita.nl (Jos Corver),

Ingmar.Nopens@UGent.be (Ingmar Nopens), Chris.Vervaet@UGent.be (Chris Vervaet), Thomas.DeBeer@UGent.be (Thomas De Beer)

URL: http://www.ugent.be/fw/pharmaceutical-analysis/en/research/pat (Laurens De Meyer)

${ }^{1}$ Phone number: +32(0)9 2648097

${ }^{2}$ Fax number: +32(0)9 2648196
} 
that approximately $50 \%$ of the approved biopharmaceutical drug products on the list of the Food and Drug Administration (FDA) and European Medicines Agency (EMA) are freeze-dried (lyophilised), indicates that freeze-drying is the preferred technology to stabilize these products 3 .

Lyophilisation is a low temperature drying process, based on the principles of mass and heat transfer, employed to convert solutions of (heat) labile materials into solids having sufficient stability for distribution and storage 4 .

Traditional freeze-drying is performed in three consecutive steps: freezing, primary drying and secondary drying [5] 8. After aseptic filling of the formulation into the vials, they are positioned on the shelves of the freeze-dryer. During the freezing step, the temperature of the shelves is decreased to approximately $-40^{\circ} \mathrm{C}$ and most of the water in the formulation crystallizes into ice, thus concentrating the solutes which are in between the ice crystals (freeze-concentration). These solutes can crystallize at the eutectic temperature $\left(T_{e u}\right)$. If no crystallization occurs, the solutes concentrate until a glass is formed at the glass transition temperature of the maximally freeze-concentrated amorphous matrix $\left(T_{g}^{\prime}\right)[9$. During primary drying, a vacuum, in general between 10 and $30 \mathrm{~Pa}$, is introduced. Subsequently the temperature of the shelves is increased to supply the energy for sublimation. It is of utter importance to keep the product temperature at the sublimation front $\left(T_{i}\right)$ below the collapse temperature $\left(T_{c}\right)$ for an amorphous product or $T_{e u}$ in case of a crystalline product during the entire primary drying process. The final step of the freeze-drying process is secondary drying where most of the unfrozen water is removed by desorption under deep vacuum and at an increased shelf temperature [10].

Freeze-drying, as it is performed these days in the pharmaceutical industry, is a batch-wise process [11. Despite the increased importance of freeze-drying, indicated by the higher number of biopharmaceuticals, it is still an expensive and time-consuming process exhibiting several disadvantages such as the uncontrolled freezing step and uneven heat transfer in the freeze-drying chamber. The disadvantages of batch-wise freezedrying have been extensively described in a previous paper from the authors [4, 9, 12. To overcome these disadvantages and to guarantee a uniform product quality, a continuous freeze-drying process has been developed.

The continuous freeze-drying process introduces two major differences compared to conventional batch freeze-drying. Firstly the freezing step, during which the vials are spun around their longitudinal axis, creating a thin frozen product layer at the vial wall (spin freezing)(Figure 1). The solution is solidified by a flow of cold, sterile gas. The thinner product layer and larger surface area of the spin frozen product significantly contributes improving the efficiency of the freeze-drying process. The second major difference occurs in the drying step where energy is homogeneously supplied towards the vial wall either by conduction (e.g. electric heating pad) or radiation (e.g. infra-red heater) 4, 13-15.

In the case of conductive drying, the energy can be provided by an electric heating pad which is wrapped

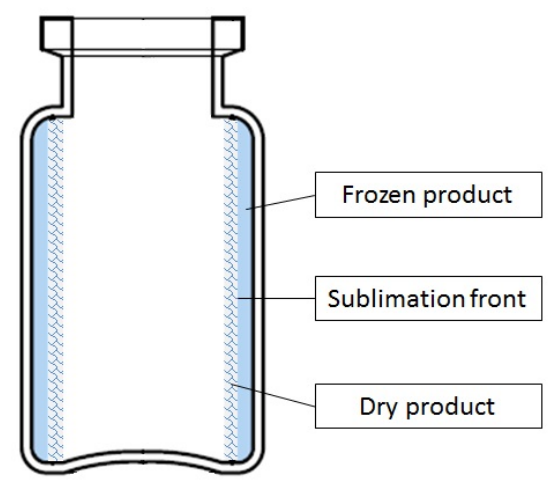

Figure 1: schematic illustration of a spin frozen vial during the drying process

around the vial creating a close contact between the vial and the heating pad for a homogeneous energy transfer (Figure 2). 
The continuous freeze-drying process is extensively described in previous work [4, 14, 15].

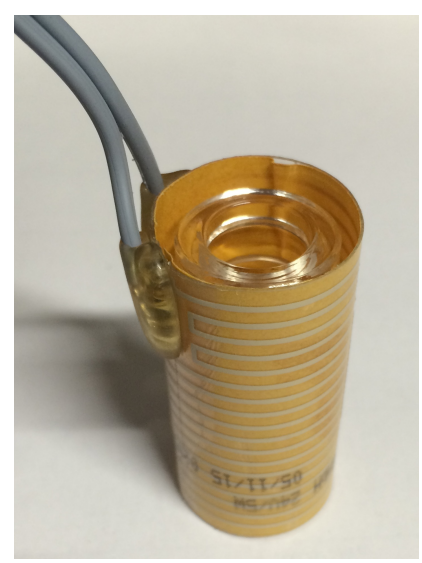

Figure 2: spin frozen vial in close contact with surrounding electric heating pad

The most critical parameter during the primary drying step is $T_{i}$. To achieve an efficient freeze-drying process, $T_{i}$ should be as high as possible during the primary drying step without exceeding $T_{c}$ or $T_{e u}$ for amorphous or crystalline materials, respectively. $T_{c}$ is in general a few degrees higher than $T_{g}^{\prime}$ since the molecular motion at $T_{g}^{\prime}$ is sufficiently low to prevent viscous flow due to the high viscosity [9]. During secondary drying, the product temperature $\left(T_{p}\right)$ should not exceed the glass transition temperature $\left(T_{g}\right)$ to avoid cake collapse. Collapse is a loss of product structure, causing a poor cake appearance and possibly impeding the reconstitution of the dried product [8, 16].

If using constant freeze-drying settings (chamber pressure and energy input for drying), $T_{i}$ would not be constant during the sublimation process because it depends on several parameters which continuously change during the process, e.g. the dried product mass transfer resistance $\left(R_{p}\right)$ [17]. When the sublimation front is moving, a dried product layer is formed, leaving behind a network of pores which create a water vapor removal resistance [18. The continuous increase of the dried product layer $(l)$ during sublimation also leads to a continuous increase in $R_{p}$. As a result, $T_{i}$ at the sublimation interface will increase when a constant energy input and freeze-dryer chamber pressure is maintained for the whole drying trajectory.

However, in order to perform sublimation as efficient as possible, it is needed to keep $T_{i}$ just below the $T_{c}$ during the entire primary drying step. Therefore, the optimal combination of energy input and chamber pressure $\left(P_{c}\right)$ is a dynamic combination during primary drying. A mechanistic model describing the primary drying step based on conductive heating, would allow the determination of the optimal combination of the heating pad temperature $\left(T_{h}\right)$ and $P_{c}$, keeping the $T_{i}$ as high as possible but still below the $T_{c}$ during the entire sublimation process.

Compared to data-driven models, which are solely based on collected experimental data, mechanistic models are based on the underlying physics governing the process [17].

This research paper focuses on the mechanistic modelling of the primary drying step allowing the calculation of the optimal dynamic settings of the electric heating pads surrounding the vial and the chamber pressure during the continuous freeze-drying process.

\section{Objectives}

There are two objectives in this paper: (1) to develop a mechanistic model describing the primary drying process of spin frozen vials via conduction using electric heating pads. This model will allow calculating the optimal dynamic freeze-drying settings for the chamber pressure and the electric heating pad temperature during the primary drying step of the freeze-drying process for a model formulation. (2) to experimentally 
verify these calculated optimal dynamic freeze-drying settings for this model formulation.

\section{Materials and methods}

3.1. Development of a mechanistic model describing primary drying during continuous lyophilisation of unit doses based on conduction via electric heating pads

Primary drying consists of two phases. The equations describing primayr drying are based on the principles of mass and energy transfer.

During the first part of the primary drying process, the pressure in the drying chamber is decreased until the desired chamber pressure (in this study) of $13.3 \mathrm{~Pa}$ is reached. Until that moment, the heating pads are turned off. The mass of ice which sublimed during the initial pressure decrease, due to energy from the surroundings, was experimentally determined (see further).

The second part of the primary drying process starts once the desired chamber pressure is reached and the heating pads are activated. During sublimation, the sublimation front moves towards the vial wall and the dried product layer increases in thickness. In traditional freeze-drying, a two-dimensional approach is necessary to model the primary drying step. In the case of continuous freeze-drying, a one-dimensional approach can be used as the product forms a conformal layer to the cylindrical vial wall. The end-effects at the bottom and top of the vial are excluded in the mechanistic model since the effect is small due to the small layer thickness.

When determining the maximum possible sublimation rate during primary drying, several limitations have to be taken into account.

The first limitation of the sublimation rate is the $R_{p}$ of the formulation. Sublimation of the ice crystals creates a network of pores in the dried product. These pores create a resistance towards the water vapour generated at the sublimation front. When more water vapour is generated than the amount that can be transferred through the dried layer, the water vapour pressure at the sublimation front will increase. As the water vapour pressure is related to $T_{i}\left(\mathrm{Eq}\right.$.5), an uncontrolled increase of $T_{i}$ is inevitable which can result in cake collapse.

The sublimation rate $\dot{m}_{s u b}(\mathrm{~kg} / \mathrm{s})$ is given by:

$$
\dot{m}_{s u b}=\frac{A_{p}}{R_{p}}\left(P_{w, i}-P_{w, c}\right)
$$

with $A p$ the surface area of the spin frozen product $\left(\mathrm{m}^{2}\right), R_{p}$ the dry product resistance $(\mathrm{m} / \mathrm{s}), P_{w, i}$ the water vapour pressure above the sublimation front $(\mathrm{Pa})$ and $P_{w, c}$ the partial water vapour pressure in the chamber $(\mathrm{Pa})$. During primary drying, the composition of the gas in the drying chamber consists almost entirely of water vapour [19]. Therefore it is assumed that $P_{w, c}$ is equal to the overall pressure in the drying chamber.

The surface area of the product during primary drying $A_{p}$ is given by:

$$
A_{p}=2 \pi h_{f}\left(r_{p, i}+l\right)
$$

with $h_{f}$ the height of the spin frozen product layer in the vial (m), $l$ the dried layer thickness $(\mathrm{m})$ and $r_{p, i}$ the radius from the center of the vial to the border of the spin frozen layer $(\mathrm{m})$, which is given by:

$$
r_{p, i}=\sqrt{r_{v, i}^{2}-\frac{V}{\pi h_{f}}}
$$

with $r_{v, i}$ the inner vial radius (m), $V$ the filling volume $\left(\mathrm{m}^{3}\right)$ and $h_{f}$ the height of the spin frozen product layer $(\mathrm{m})$. 
$R_{p}$, another parameter in equation 1 depends on the thickness of the dried product layer $l(\mathrm{~m})$. The following equation describes the link between $R_{p}(\mathrm{~m} / \mathrm{s})$ and the dried layer thickness $l[20$ :

$$
R_{p}=R_{p, 0}+\frac{A_{R p} l}{1+B_{R p} l}
$$

with $R_{p, 0}(\mathrm{~m} / \mathrm{s}), A_{R p}(1 / \mathrm{s})$ and $B_{R p}(1 / \mathrm{m})$ parameters, which are dependent on the composition of the freeze-dried product, its concentration and the freezing step [21 23]. These parameters are determined experimentally by fitting to experimental data.

$R_{p}$ increases when $l$ increases during the primary drying step (Eq. 13). In order to keep $T_{i}$ below the collapse temperature of the product, in most cases the energy input needs to decrease during primary drying.

The driving force for ice sublimation is the pressure difference between the water vapour pressure at the sublimation front $P_{w, i}$ and the water vapour pressure in the freeze-dryer chamber $P_{w, c}$ which can be adjusted. $P_{w, i}$ is calculated by the following equation [24]:

$$
P_{w, i}=2.710^{10} \mathrm{e}^{\frac{-6145}{T_{i}}}
$$

with $T_{i}$ the product temperature at the sublimation front $(\mathrm{K})$.

To optimize the drying efficiency without losing an elegant cake structure, $T_{i}$ is targeted to be equal to but not exceeding - the glass transition temperature $T_{g}^{\prime}$.

In most cases, $T_{c}$ is several degrees higher than $T_{g}^{\prime}$ as the high viscosity of the sample close to $T_{g}^{\prime}$ prevents viscous flow 9 .

The second limitation of the sublimation rate next to $R_{p}$ is the choked flow limit. Choked flow is described as a loss of pressure control due to equipment limitation, at the level of the vial neck or at the level of the duct connecting the chamber with the condenser 25]. For batch freeze-drying, the duct connecting the chamber with the condenser is the most critical point where choked flow can occur. More precisely at the narrowest point of the duct, being the valve separating the drying chamber from the condenser. The gas flow through the vial neck is low due to the low sublimation rate but the freeze-dryer contains a lot of vials creating a high gas flow at the condenser duct. During continuous freeze-drying, the amount of vials being processed at the same time in the equipment is smaller but the gas flow through the vial neck is higher compared to batch freeze-drying due to the larger product surface area. Choked flow occurs once the vapour flow rate through the vial neck approaches the speed of sound, where a further increase in mass flow would result in an elevated vapour density, leading to a local pressure increase inside the vial. From the relationship between temperature at the sublimation front and the corresponding pressure, it can be deduced that a higher pressure leads to a higher temperature at the sublimation front. This temperature increase will lead to local exceeding of the product temperature and potential collapse. A safety factor of $30 \%$ is taken into account to calculate the maximal speed of the gas flow $\left(v_{\text {sound,safe }}\right)$.

The choked flow condition is calculated with the following equations:

$$
\begin{gathered}
c=\sqrt{\frac{\gamma R T_{w v}}{M}} \\
v_{\text {sound,safe }}=0.3 c \\
V_{\text {max }}=v_{\text {sound }, \text { safe }} \pi\left(d_{v, o} / 2\right)^{2} \\
\dot{m}_{\text {max }}=V_{\text {max }} \rho_{w v}
\end{gathered}
$$

with $c$ the velocity of sound $(\mathrm{m} / \mathrm{s}), \gamma$ the adiabatic constant for a triatomic gas $(-), \mathrm{R}$ the molar gas constant $(\mathrm{J} / \mathrm{mol} \mathrm{K}), T_{w v}$ the temperature of the water vapour, M the molar mass of water $(\mathrm{kg} / \mathrm{mol})$, $v_{\text {sound,safe }}$ the safe velocity of sound $(\mathrm{m} / \mathrm{s}), V_{\max }$ the maximum volume of sublimed gas $\left(\mathrm{m}^{3} / \mathrm{s}\right), d_{v, o}$ the diameter of the vial opening $(\mathrm{m}), \dot{m}_{\max }$ the maximum mass of sublimed gas $(\mathrm{kg} / \mathrm{s})$ and $\rho_{w v}$ the density of the water vapour $\left(\mathrm{kg} / \mathrm{m}^{3}\right)$. 
The density of the water vapour $\rho_{w v}\left(\mathrm{~kg} / \mathrm{m}^{3}\right)$ is given by:

$$
\rho_{w v}=\frac{P_{w v} M}{R T_{w v}}
$$

with $P_{w v}$ the water vapour pressure above the sublimation front (Pa), M the molar mass of water $(\mathrm{kg} / \mathrm{mol})$, $\mathrm{R}$ the molar gas constant $(\mathrm{J} / \mathrm{mol} \mathrm{K})$ and $T_{w v}$ the temperature of the water vapour $(\mathrm{K})$.

$\dot{m}_{s u b}$ (calculated by equation 1) has to be compared with $\dot{m}_{\max }$ to ensure the choked flow criterium is not violated. If $\dot{m}_{s u b}$ would be higher than $\dot{m}_{\max }, \dot{m}_{s u b}$ is to be fixed at $\dot{m}_{\max }$ in Eq 1. Based on $\dot{m}_{s u b}$ the power that should be provided to the vial to sublimate the ice $\left(P_{\text {sub }}\right)(\mathrm{J} / \mathrm{h})$ can be calculated:

$$
P_{s u b}=\dot{m}_{s u b} \Delta H_{s}
$$

with $\dot{m}_{\text {sub }}$ the sublimation rate $(\mathrm{kg} / \mathrm{h})$ and $\Delta H_{s}$ the latent heat of ice $(\mathrm{J} / \mathrm{kg})$.

The electric heating pad temperature to be $\operatorname{set}\left(T_{h}\right)$ corresponding to $P_{\text {sub }}$ is given by:

$$
T_{h}=\frac{P_{s u b}}{A_{p} K_{v}}+T_{v}
$$

with $P_{s u b}$ the power needed to sublimate the ice $(\mathrm{J} / \mathrm{h}), A_{p}$ the surface area of the spin frozen product $\left(\mathrm{m}^{2}\right), K_{v}$ the heat transfer coefficient $\left(\mathrm{J} / \mathrm{m}^{2} \mathrm{sK}\right)$ and $T_{v}$ the temperature of the vial $(\mathrm{K})$. The maximum temperature of the heating pad used in this study is restricted to $80^{\circ} \mathrm{C}$. This value depends on the type of heating pad. The temperature ramp of the used heating pad $\left(18^{\circ} \mathrm{C} / \mathrm{min}\right)$ at the start of primary drying is taken into account.

Finally, the increase in the dried layer thickness $(\Delta l)$ for a specified time interval $\Delta t$ (h) is given by:

$$
\frac{\Delta l}{\Delta t}=\frac{\dot{m}_{s u b}}{A_{p} \rho_{i c e} \phi}
$$

with $\dot{m}_{\text {sub }}$ the sublimation rate $(\mathrm{kg} / \mathrm{h}), A_{p}$ the surface area of the product $\left(\mathrm{m}^{2}\right), \rho_{\text {ice }}$ the density of ice $\left(\mathrm{kg} / \mathrm{m}^{3}\right)$ and $\phi$ the volume fraction of ice (-).

These calculations are repeated for the next layer thickness (previous dry layer thickness + increase in dry layer thickness). This calculated total dry layer thickness is increasing in time and the simulation is ended when the sum of the dried layer thicknesses equals the initial layer thickness after spin freezing of the product.

$R_{p}$ depends on the dry layer thickness (Eq. 4) thus leading to an $R_{p}$ which is changing in time during primary drying. This affects the maximum amount of power which can be transferred towards the product at every time step. The output of the mechanistic model is the optimal dynamic temperature profile of the electric heating pad every process minute during primary drying.

It was chosen from a practical point of view to predict the optimal dynamic temperature profile of the electric heating pad surface instead of the optimal dynamic power profile because some energy input of the heating pads is lost towards the environment and because some energy is used for heating the heating pad itself. It was impossible to quantify and model this energy loss.

Furthermore for the type of heating pad used in this study it was not possible to calibrate for the power input and the temperature output of the electric heating pad. Herewith was the by the model predicted dynamic temperature profile set under PID control. The by a thermocouple measured process variable is the electric heating pad temperature which is the result of the power input controlled by the PID algorithm.

\section{2. $K v$ determination of the electric heating pad}

The heat transfer coefficient between a shelf and the bottom of a vial for batch freeze-drying consists of the sum of three terms [26]:

$$
K_{v}=K_{c}+K_{r}+K_{g}
$$


with $K_{v}$ the overall heat transfer coefficient between the shelf and the vial, $K_{c}$ the heat transfer coefficient for the direct conduction from the shelf to the vial at the contact points, $K_{r}$ the heat transfer coefficient for the radiation and $K_{g}$ the heat transfer coefficient from the conduction through the gas. The same equation is used for the conductive drying with electric heating pads where $K_{c}$ is the heat transfer coefficient for the direct conduction from the electric heating pad to the vial at the contact points. The heat transfer coefficient $K_{v}$ of the electric heating pads to the applied vials (see further) was determined by performing different spin frozen pure ice sublimation experiments at different pressure levels [26]. A 10R vial containing $3 \mathrm{~mL}$ water was spin frozen and freeze-dried. Three different pressure levels were tested: $10 \mathrm{~Pa}, 20 \mathrm{~Pa}$ and 30 Pa. The Amsco Finn-Aqua GT4 freeze-dryer (GEA, Köln, Germany) was used as a vacuum chamber. After spin freezing, the vial was placed inside the cylinder formed by the electric heating pad within $15 \pm 5$ sec and transfered to the chamber of the freeze-dryer. The electric heating pad was installed under a pre-cooled shelf $\left(-10^{\circ} \mathrm{C}\right)$ to avoid contact with the shelves (Figure 3). The energy for sublimation was provided by the electric heating pad, which was wrapped around the vial, and was also kept constant during the experiment $(10 \mathrm{~V}, 0.10 \mathrm{~A})$.

After 30 minutes of primary drying, the process was interrupted by venting the chamber with dry nitrogen gas and the mass of sublimed ice was gravimetrically determined. Based on this mass of sublimed ice and the primary drying time, the sublimation rate $\dot{m}_{s u b}$ was calculated. The experiment was performed in triplicate at each pressure level. The product temperature $\left(T_{i}\right)$ and heating pad temperature $\left(T_{h}\right)$ were monitored with Type-K thermocouples (WIKA instruments, Klingenberg, Germany) which were pressed against the ice inside the vial and against the external part of the heating pad, respectively. $K_{v}$ was calculated after each experiment using the following equation:

$$
K_{v}=\frac{\dot{m}_{s u b} \Delta H_{s}}{A_{v} M\left(T_{h}-T_{i}\right)}
$$

with $\dot{m}_{s u b}$ the sublimation rate $(\mathrm{kg} / \mathrm{s}), \Delta H_{s}$ the latent heat of ice $(\mathrm{J} / \mathrm{kg}), A_{v}$ the surface area of the vial $\left(\mathrm{m}^{2}\right)$, M the molar mass of water $(\mathrm{kg} / \mathrm{mol}), T_{h}$ the temperature of the electric heating pad $(\mathrm{K})$ and $T_{i}$ the product temperature at the sublimation front $(\mathrm{K})$.

To obtain the parameters describing $K_{v}$ as function of $P_{c}$, nonlinear regression was used to fit the following equation to the obtained data from the above $K_{v}$ experiments where $K_{v}$ was plotted for the different pressure levels. The equation is adapted from literature [6, 16, 27.

$$
K_{v}=\alpha+\frac{\beta P_{c}}{1+\gamma P_{c}}
$$

with $\alpha\left(\mathrm{J} /\left(\mathrm{m}^{2} \mathrm{sK}\right), \beta\left(\mathrm{J} /\left(\mathrm{m}^{2} \mathrm{sKPa}\right)\right.\right.$ and $\gamma(1 / \mathrm{Pa})$ parameters describing $K_{v}$ quantitatively in function of $P_{c}$.

\subsection{Experimental model validation}

The above developed model allowing the calculation of the dynamic heating pad settings during primary drying was applied and verified for a model formulation. The model formulation consisted of mannitol $30 \mathrm{mg} / \mathrm{ml}$, sucrose $3.42 \mathrm{mg} / \mathrm{ml}$, glycine $3.75 \mathrm{mg} / \mathrm{ml}$ and sodium chloride $0.58 \mathrm{mg} / \mathrm{ml}$. Mannitol, sucrose and glycine were purchased from Sigma-Aldrich (Saint Louis, MO, USA). Sodium chloride was purchased from Fagron (Waregem, Belgium).

A 10R type I glass vial (Schott, Müllheim, Germany) was filled with $3.0 \mathrm{~mL}$ of the formulation and spin frozen as reported by De Meyer et al. 4]. After spin freezing, the vial was placed inside the cylinder formed by the electric heating pad and transfered to the chamber of the freeze-dryer within $15 \pm 5$ sec . The electric heating pad was installed under a pre-cooled shelf $\left(-10^{\circ} \mathrm{C}\right)$ to avoid contact with the shelves (Figure 3). When the desired pressure level was reached $(13.3 \mathrm{~Pa})$, the programmed dynamic temperature profile as calculated in section 3.1 was started. The mass of ice which already sublimed before the desired pressure level was reached is experimentally determined and the initial mass of ice is corrected by this value in the mechanistic model. The values of the input parameters used for the calculations of the dynamic temperature 
profile are overviewed in table 1. The product resistance parameters were adopted from literature 28. The drying process was monitored with in-line NIR spectroscopy to determine the primary drying endpoint 4. The last temperature value of the dynamic temperature profile was maintained for 30 minutes to ensure that primary drying completely finished to determine the endpoint of primary drying with NIR spectroscopy. The experimental model verification was repeated six times.

Table 1: Nominal values of the input parameters to calculate the dynamic temperature profile of the electric heating pads

\begin{tabular}{c|c} 
Parameter & Numerical value \\
\hline$\Delta H_{s}$ & $2838 \mathrm{~J} / \mathrm{g}$ \\
$M$ & $0.018015 \mathrm{~kg} / \mathrm{mol}$ \\
$R$ & $8.3144621 \mathrm{~J} / \mathrm{mol} \mathrm{K}$ \\
$\gamma$ & 1.33 \\
$\rho_{i c e}$ & $918 \mathrm{~kg} / \mathrm{m}^{3}$ \\
$\rho_{\text {sol }}$ & $1000 \mathrm{~kg} / \mathrm{m}^{3}$ \\
$\phi$ & 1 \\
Vial inner radius $r_{v, i}$ & $0.0109 \mathrm{~m}$ \\
Filling volume V & $3.0 \mathrm{~mL}$ \\
Heat transfer coefficient $K_{v}$ & $14.94 \mathrm{~J} / \mathrm{m}^{2} \mathrm{sK}$ \\
Product resistance parameter $R_{p, 0}$ & $1.8510^{4} \mathrm{~m} / \mathrm{s}$ \\
Product resistance parameter $A_{R p}$ & $1.2010^{7} 1 / \mathrm{s}$ \\
Product resistance parameter $B_{R p}$ & $-6.76101 / \mathrm{m}$ \\
Glass transition temperature max concentrated formulation $\mathrm{Tg}$, & $240.15 \mathrm{~K}$
\end{tabular}

\subsection{NIR spectroscopy}

To determine the endpoint of primary drying of the model formulation in the spin frozen vials, an NIR probe coupled to a fourier-transform near-infrared (FT NIR) spectrometer (Thermo Fisher Scientific, Zellik, Belgium, Nicolet Antaris II near-IR analyzer) was implemented in the drying chamber of the freeze-dryer and placed against the vial through a small hole $\left(32 \mathrm{~mm}^{2}\right)$ in the electric heating pad (Figure 3). The diffuse reflectance NIR spectra were collected in a continuous and non-invasive way during the in-line NIR experiments. The NIR spectrometer was equipped with an InGaAS detector, a quartz halogen lamp and a fiber-optic non-contact probe which was brought into the drying chamber through a vacuum feedthrough in the sidewall of the chamber. Spectra were taken from $10000 \mathrm{~cm}^{-1}$ to $4500 \mathrm{~cm}^{-1}$ with a resolution of $8 \mathrm{~cm}^{-1}$ and averaged over 32 scans. Every process minute, a spectrum was recorded. The NIR probe was positioned in front of the hole in the electric heating pad. The sidewall of the vial was hence monitored with a spot size of about $28 \mathrm{~mm}^{2}$. The effective sample size measured by the NIR probe hence consisted of a small part of the total sample volume $(3.0 \mathrm{ml})$ but it was assumed that this part is representative for the whole product. It was from a practical point of view not possible and also not desired (since non-contact measurements are preferred) to bring the NIR probe inside the vial.

\subsection{Multivariate data analysis}

Principal Component Analysis (PCA) was applied to analyze the in-line collected NIR spectra using a multivariate data analysis software package (Simca 14.1, Umetrics AB, Umeå, Sweden). The spectra taken before activation of the electric heating pad were deleted from the dataset. The $10000 \mathrm{~cm}^{-1}$ to $7500 \mathrm{~cm}^{-1}$ region was also excluded from the dataset since this region does not contain valuable spectral information. The spectra were preprocessed using Standard Normal Variation (SNV) to eliminate the additive baseline offset variations and multiplicative scaling effects in the spectra [29], Savitzky-Golay filtering (quadratic polynomial function fitted to moving sub-model, each containing fifteen data points) and mean centering prior to analysis. 


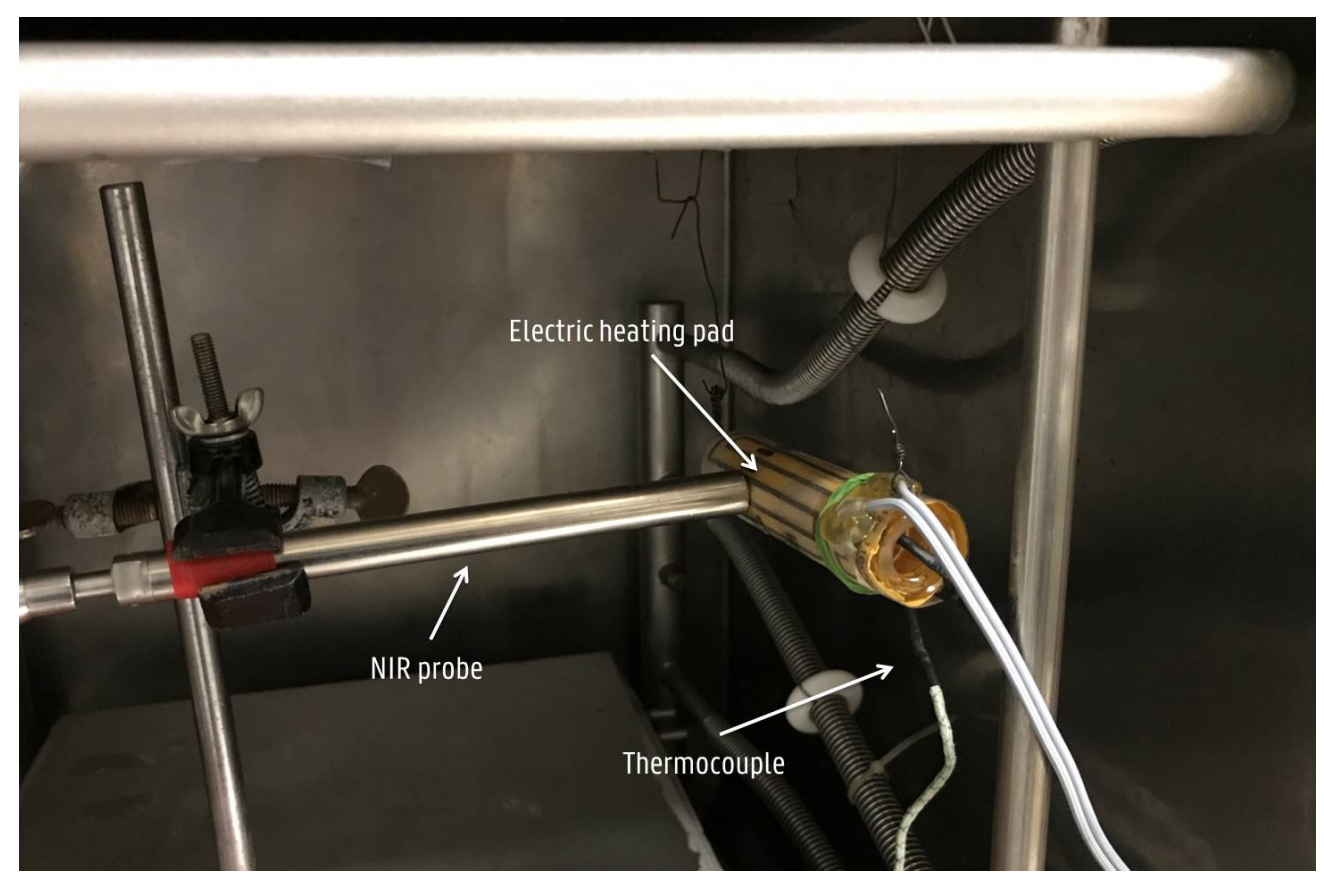

Figure 3: Experimental setup to monitor the freeze-drying process with NIR

PCA produces an orthogonal bilinear data matrix decomposition, where principal components (PCs) are obtained in a sequential way to explain maximum variance:

$$
D=T P^{\mathrm{T}}+E=t_{1} p_{1}^{\prime}+t_{2} p_{2}^{\prime}+\ldots+t_{Q} p_{Q}^{\prime}+E
$$

where $\mathrm{T}$ is the $\mathrm{M} x \mathrm{Q}$ score matrix, $\mathrm{P}$ the $\mathrm{N} x \mathrm{Q}$ loading matrix, $\mathrm{E}$ the $\mathrm{M} \times \mathrm{N}$ model residual matrix, $\mathrm{Q}$ the number of PCs, $\mathrm{N}$ the number of collected spectra at M wavelengths. Each PC consists of two vectors, the score vector $\mathrm{t}$ and the loading vector $\mathrm{p}$. The score vector contains a score value for each spectrum, and this value informs how the spectrum is related to the other spectra in that particular component. The loading vector indicates which spectral features in the original spectra are captured by the component studied. These unique and orthogonal PCs can be very helpful in deducing the number of different sources of variation present in the data and the occurrence of groups of related objects. However, these PCs do not necessarily correspond to the true underlying factors causing the data variation, since each PC is obtained by maximizing the amount of remaining variance [30].

\subsection{Determination of the glass transition temperature of the maximally freeze concentrated formulation Tg'}

The thermal behaviour of the model formulation was evaluated via Modulated Differential Scanning Calorimetry (MDSC) using a Differential Scanning Calorimeter (DSC) Q2000 V24.11 equipped with a RCS90 refrigerated cooling system (TA Instruments, Leatherhead, UK). Nitrogen was used as the purge gas through the DSC cell $(50 \mathrm{ml} / \mathrm{min})$ and the RCS unit $(300 \mathrm{ml} / \mathrm{min})$. Samples $( \pm 10 \mathrm{mg})$ were run in hermetically closed standard aluminium pans supplied by TA Instruments. Mass of the sample pan and empty reference pan were taken into account. The experimental method consisted of an initial $5 \mathrm{~min}$ isothermal equilibration period at $-90^{\circ} \mathrm{C}$. During the subsequent heating run an underlying heating rate of $2^{\circ} \mathrm{C} / \mathrm{min}$ from $-90^{\circ} \mathrm{C}$ to $0^{\circ} \mathrm{C}$, a modulation amplitude of $0.318^{\circ} \mathrm{C}$ and a period of $60 \mathrm{~s}$ were applied. Temperature and enthalpic calibration was performed with an indium standard, whereas calibration of the heat capacity was performed with a sapphire standard. The experiment was replicated in triple. The glass transition temperature $\left(T_{g}^{\prime}\right)$ was calculated as inflection point using the TA Instruments Universal Analysis 2000 V4.5A Software. 


\section{Results and discussion}

\subsection{Output primary drying model for the continuous freeze-drying process}

The mechanistic primary drying model allows predicting the optimal dynamic temperature profile of the electric heating pads required for as efficient as possible primary drying of spin frozen vials without cake collapse. The calculated optimal temperature of the electric heating pad $T_{h}$ is plotted in function of the primary drying time $t$ for the studied model formulation (Figure 4). It was experimentally determined that $0.131310^{-3} \mathrm{~kg}$ ice sublimed during the initial pressure decrease. For this reason, the dried layer thickness $l$ does not start at zero at the start of primary drying. After 52 minutes 30 seconds of primary drying, the calculated $l$ equals the initial total layer thickness $(1.6 \mathrm{~mm})$ indicating the end of primary drying. After placing the spin frozen vial in the electric heating pad, the heating pad is cooled by the in liquid nitrogen spin frozen vial. The initial $T_{h}$ is $-10^{\circ} \mathrm{C}$ and equals the temperature of the frozen vial when the primary drying vacuum level is reached $(13.3 \mathrm{~Pa})$. This implicates that the product temperature exceeded $T_{g}^{\prime}$ during 7 to 8 minutes which possibly resulted in annealing. The optimal calculated heating pad temperature of the heating pad increases towards the maximum $T_{h}$ of $80^{\circ} \mathrm{C}$ at the maximal temperature ramp for this type of heating pad, being $18^{\circ} \mathrm{C} / \mathrm{min}$. Due to the increasing $R_{p}$ during primary drying, $T_{h}$ gradually decreases to $30.65^{\circ} \mathrm{C}$ at the end of primary drying. Hence the $T_{h}$ setpoint depends on $R_{p}$. At the beginning of primary drying (after the temperature ramp up), $R_{p}$ is low, hence allowing a high $T_{h}$. As primary drying progresses, $R_{p}$ increases resulting in a lower allowed energy input to avoid cake collapse.

During the experimental validation it became clear that the maximum heating pad temperature of $80^{\circ} \mathrm{C}$ could not be reached due to limitations of the heating pad used. The maximum reachable temperature appeared to be $50^{\circ} \mathrm{C}$. This heating pad temperature restriction is inherently coupled to a longer primary drying time being $56 \mathrm{~min} 40 \mathrm{sec}$. This dynamic heating pad temperature as function of primary drying time is plotted in figure 5 .

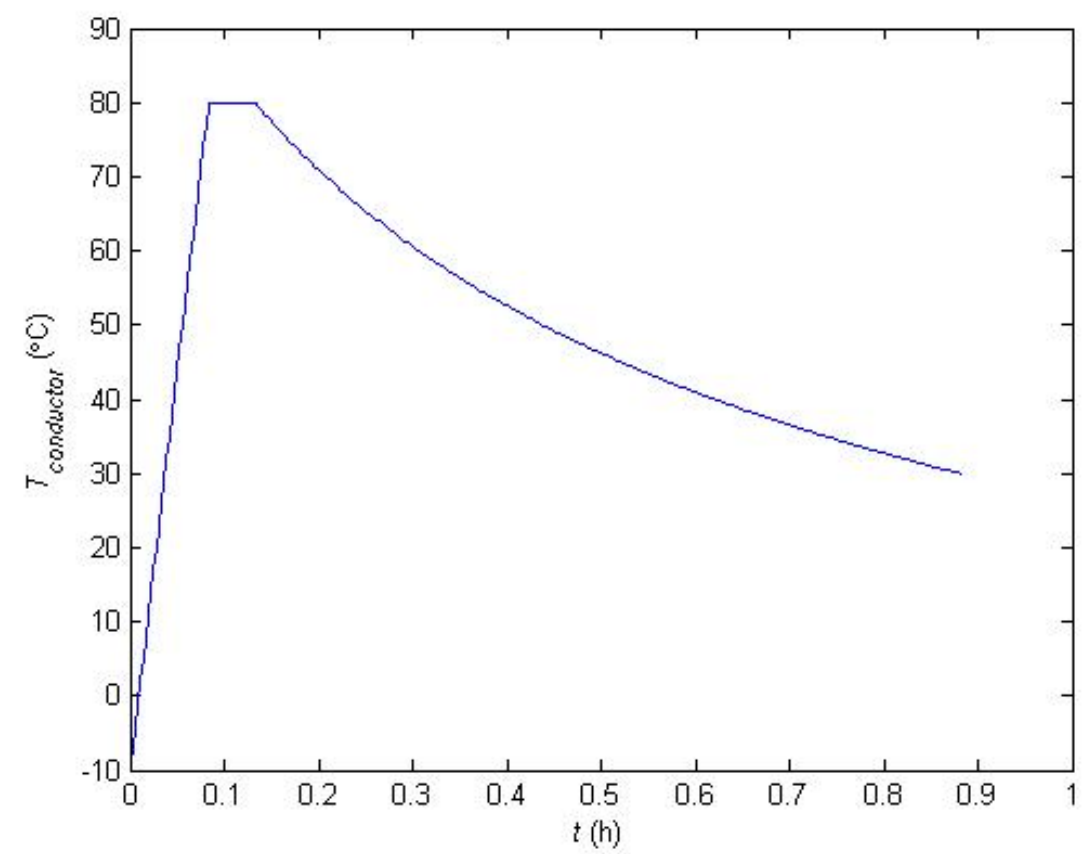

Figure 4: Dynamic heating pad temperature $T_{h}$ as function of primary drying time $t$. The heating pad temperature was restricted to $80^{\circ} \mathrm{C}$ 


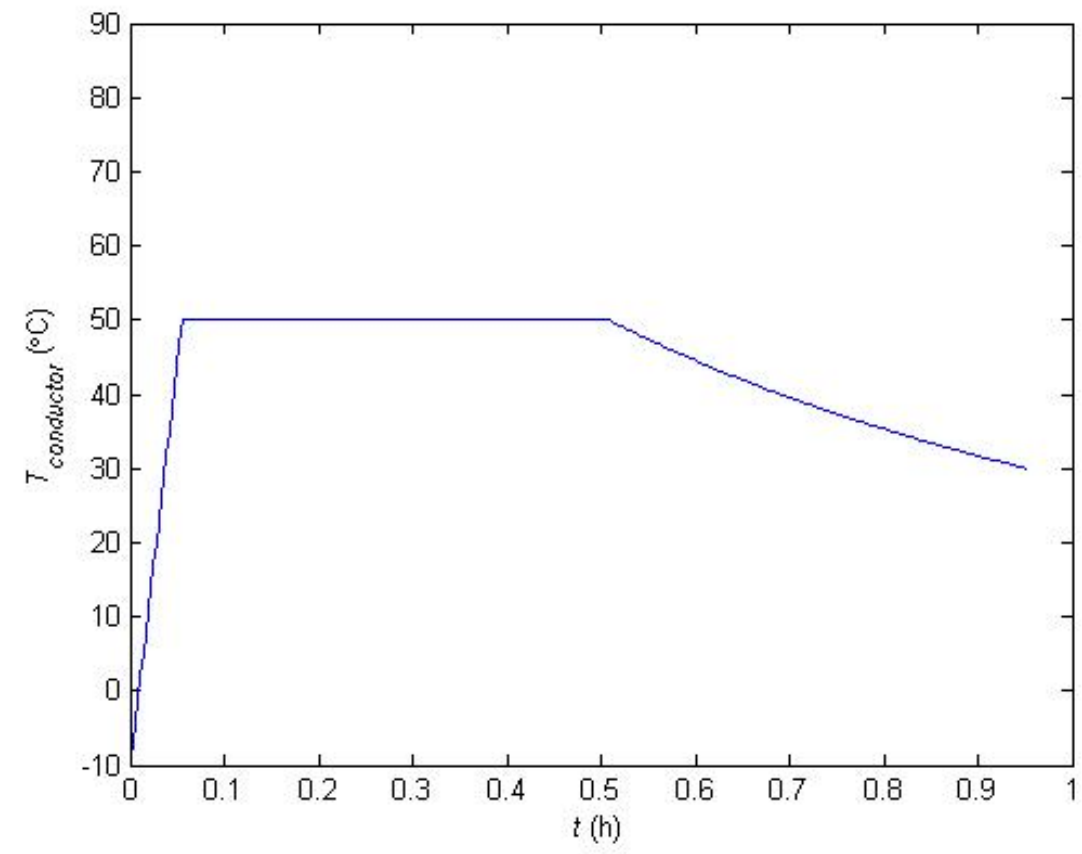

Figure 5: Dynamic heating pad temperature $T_{h}$ as function of primary drying time $t$. The heating pad temperature was restricted to $50^{\circ} \mathrm{C}$

\section{2. $K_{v}$ determination of electric heating pads}

The results of the $K_{v}$ experiments (Table 2 revealed no significant difference in $K_{v}\left(14.94 \mathrm{~J} / \mathrm{m}^{2} \mathrm{sK}\right)$ for the different tested pressure levels.

Table 2: Experimentally determined $K_{v}$ values at three different pressure levels for a $10 \mathrm{R}$ vial surrounded by an electric heating pad

\begin{tabular}{c|cc} 
Chamber pressure $(\mathrm{Pa})$ & $K_{v}\left(\mathrm{~J} / \mathrm{m}^{2} \mathrm{sK}\right)$ & $\mathrm{SD}\left(\mathrm{J} / \mathrm{m}^{2} \mathrm{sK}\right)$ \\
\hline 10 & 14.75 & 1.30 \\
20 & 14.97 & 0.99 \\
30 & 15.09 & 1.03
\end{tabular}

The close contact between the electric heating pad and the entire vial wall reduces the contribution of the gas conduction $\left(K_{g}\right)$ component to $K_{v}$, making this parameter independent of the chamber pressure. The radiation $\left(K_{r}\right)$ component is also minimalised due to shielding of the vial by the electric heating pad. This is confirmed by the $K_{v}$ determination experiments.

Since these experiments revealed that $K_{v}$ is independent of $P_{c}, P_{c}$ is fixed at $13.3 \mathrm{~Pa}$ in the mechanistic model. Eq. 1 defines the relation between $\dot{m}_{s u b}$ and $P_{w, c}$ where the difference between $P_{w, i}$ and $P_{w, c}$ is the driving force for sublimation. To calculate the optimal dynamic heating pad temperature, within the chamber pressure range of $10-30 \mathrm{~Pa}$, a pressure of $13.3 \mathrm{~Pa}$ was chosen as chamber pressure value in the mechanistic model. $10 \mathrm{~Pa}$ should provide a higher sublimation rate (driving force $\left(P_{w, i}-P_{w, c}\right)$ increases) but due to the in-line NIR measurements (i.e., NIR probe interfacing in the drying chamber), the minimal reachable $P_{c}$ is $13.3 \mathrm{~Pa}$. 


\subsection{Experimental model validation}

All model validation runs $(\mathrm{n}=6)$ were continuously monitored with in-line NIR spectroscopy. PCA and interpretation was done according to the method described by De Meyer et al. 44. After preprocessing and PCA of the collected NIR spectra, a scores scatter plot was created for each validation run. Figure 6 shows the scores scatter plot ( $\mathrm{PC} 1$ versus $\mathrm{PC} 2$ ) of the first experiment. $75.5 \%$ of the spectral variation is captured in the first principle component. The second principle component covers $22.3 \%$ of the spectral variation. All validation runs were analyzed as described below and similar trends could be seen. The scores scatter plots and loading plots of the other validation runs are not shown.

Looking at the loading line plots of $\mathrm{PC} 1$ and $\mathrm{PC} 2$ (figure 7 and 8 respectively), the band at $5160 \mathrm{~cm}^{-1}$ is

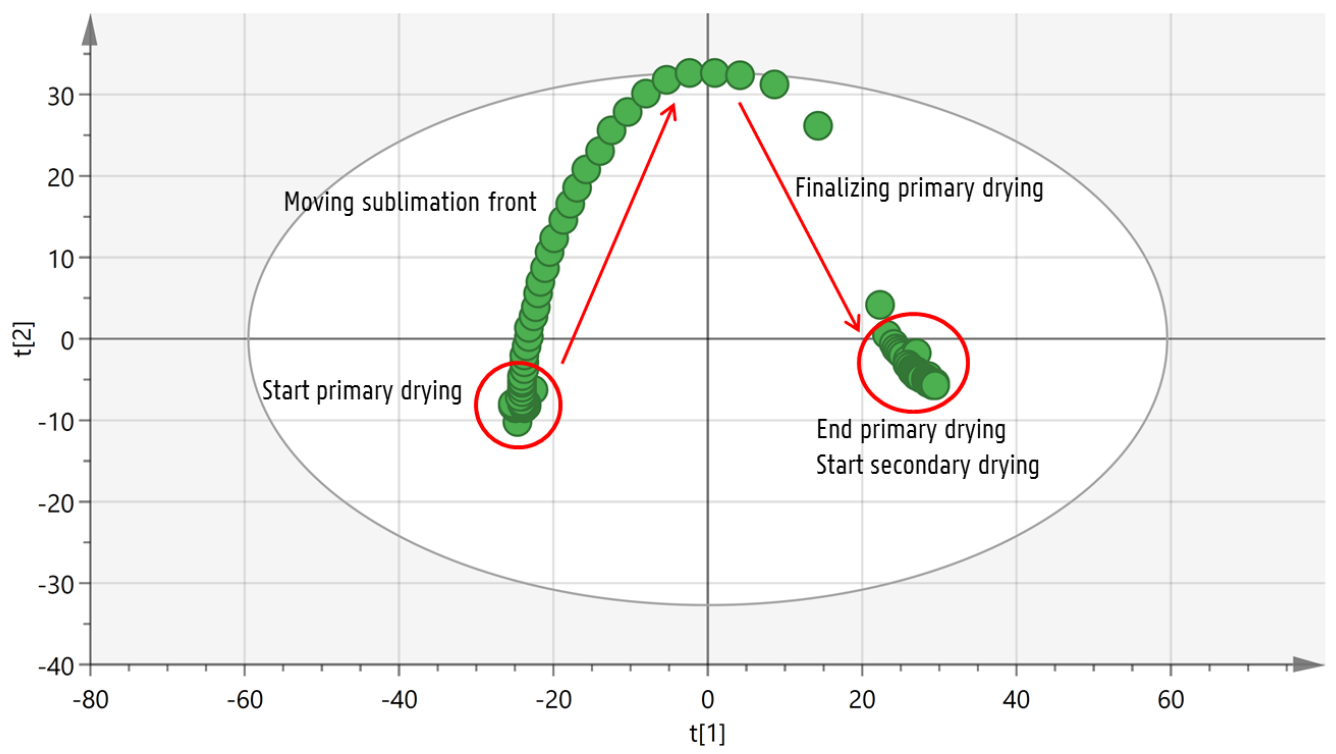

Figure 6: Scores scatter plot after principle component analysis of the first verification experiment

facing downwards for $\mathrm{PC} 1$ and upwards for $\mathrm{PC} 2$. This band is the result of a combination of $\mathrm{O}-\mathrm{H}$ stretching and $\mathrm{H}-\mathrm{O}-\mathrm{H}$ bending vibrations of water 31 . A broad band can be noticed between $5500 \mathrm{~cm}^{-1}$ and $7000 \mathrm{~cm}^{-1}$ with a maximum at $6700 \mathrm{~cm}^{-1}$ which is typical for ice in the formulation. It originates from symmetric and asymmetric stretch of ice. This band faces downwards in PC1 and upwards in PC2. Scores moving in the positive direction along $\mathrm{PC} 1$ and the negative direction of $\mathrm{PC} 2$ indicate the removal of ice from the formulation.

The loadings of these PCs indicate that the trajectory of the score plot originates from changes in the ice and water content in the formulation during the freeze-drying process, allowing the determination of the primary and secondary drying endpoint [4].

In depth analysis of the scores scatter plot reveals that at the start of primary drying the scores are clustered, indicating there were no changes in the spectra during the start of primary drying. Only the overwhelming ice bands are visible in the NIR spectra (figure 99). Ice sublimation occurs at this moment but as sublimation starts at the top of the frozen product layer (i.e. on the inner side of the vial) this is not detected by the NIR probe which is positioned at the outside of the vial.

After 18 minutes of primary drying, the scores start moving in a positive direction on the PC2 axis. The intensity of the NIR bands around $5160 \mathrm{~cm}^{-1}$ and $6700 \mathrm{~cm}^{-1}$ starts to increase (figure 9a). This is confirmed by the loading line plot of $\mathrm{PC} 2$ where both bands are faced upwards. This could be explained by the decreasing ice layer thickness and the fact that the sublimation front is moving towards the NIR probe. The NIR light only has a limited penetration depth and the ice signals overwhelm the spectra until the decreasing ice layer thickness allowed the detection of underlying water and formulation-characteristic excipient bands.

At the first inflection point, the primary drying had progressed to such an extent that the sublimation front 


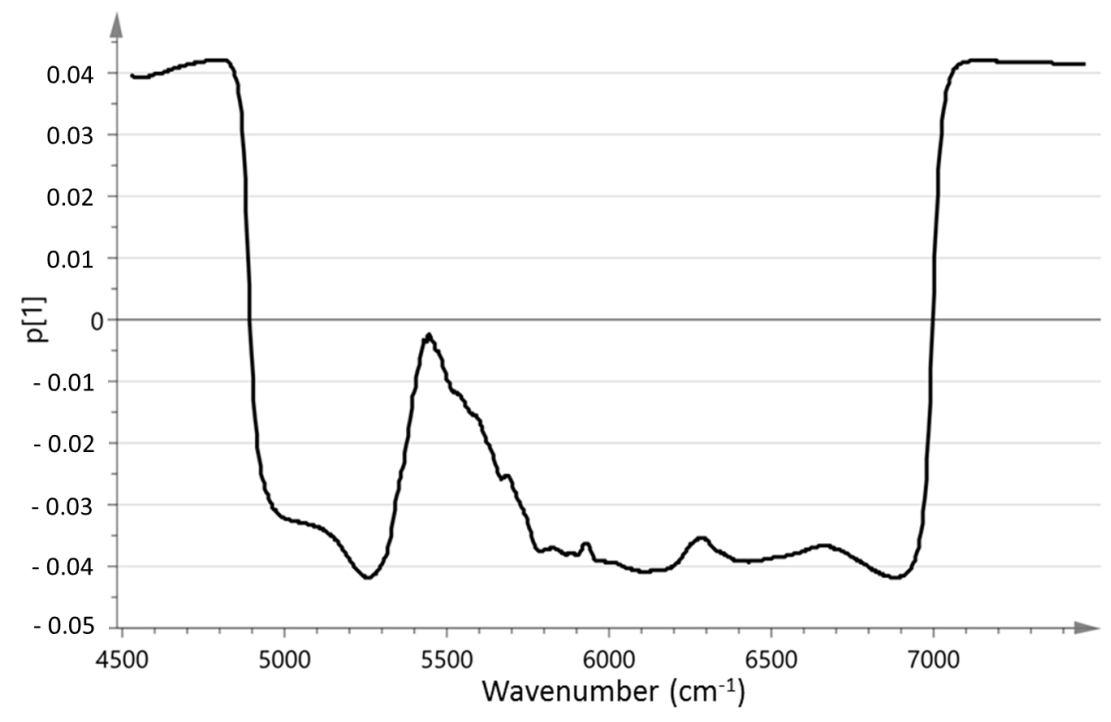

Figure 7: Loading line plot of PC1

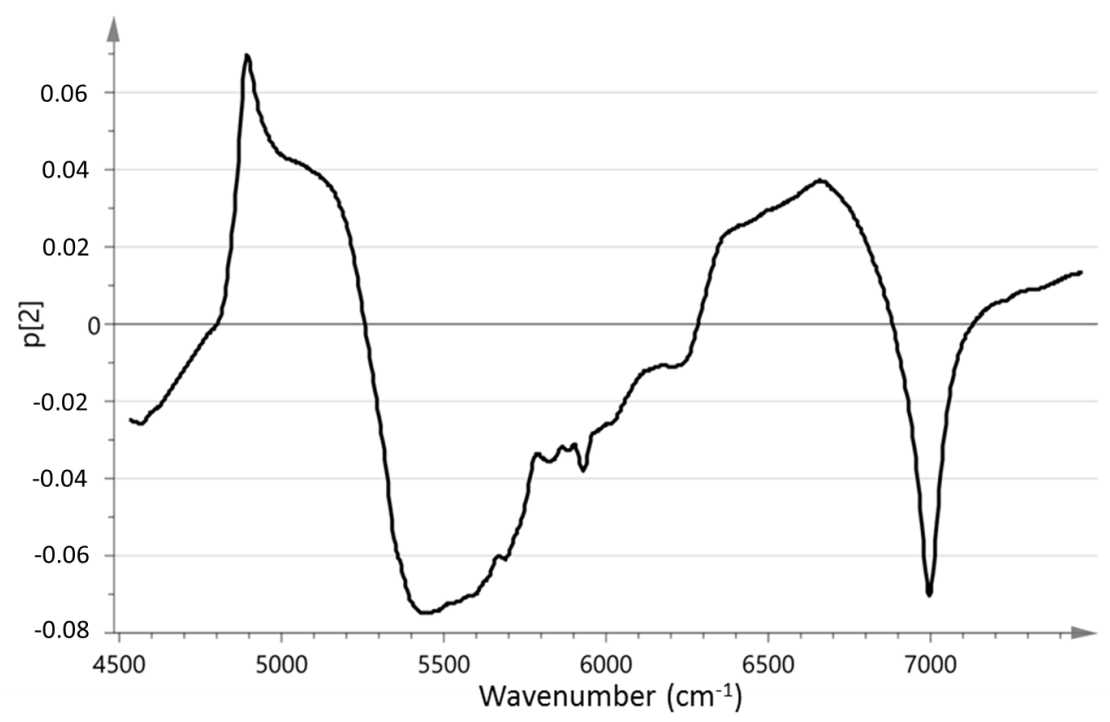

Figure 8: Loading line plot of PC2

was within sight of the NIR probe, and the water band and characteristic excipient bands appear in the spectra. Ice bands are still visible in the spectra but their intensity is reduced (figure 9p).

Between the inflection point and the second cluster of scores, the primary drying process is finalizing. The scores move in a negative direction along PC2 and a positive direction along PC1. The ice bands in the loading plot of $\mathrm{PC} 2$ are facing upwards and downwards in $\mathrm{PC} 1$ so this movement along $\mathrm{PC} 1$ and $\mathrm{PC} 2$ indicates the complete removal of ice.

The second cluster formed by the scores indicates the endpoint of primary drying. Secondary drying starts during the finalization of primary drying and is visualized by a decrease of the free water band at $5160 \mathrm{~cm}^{-1}$ (figure 96) [4, 31. 

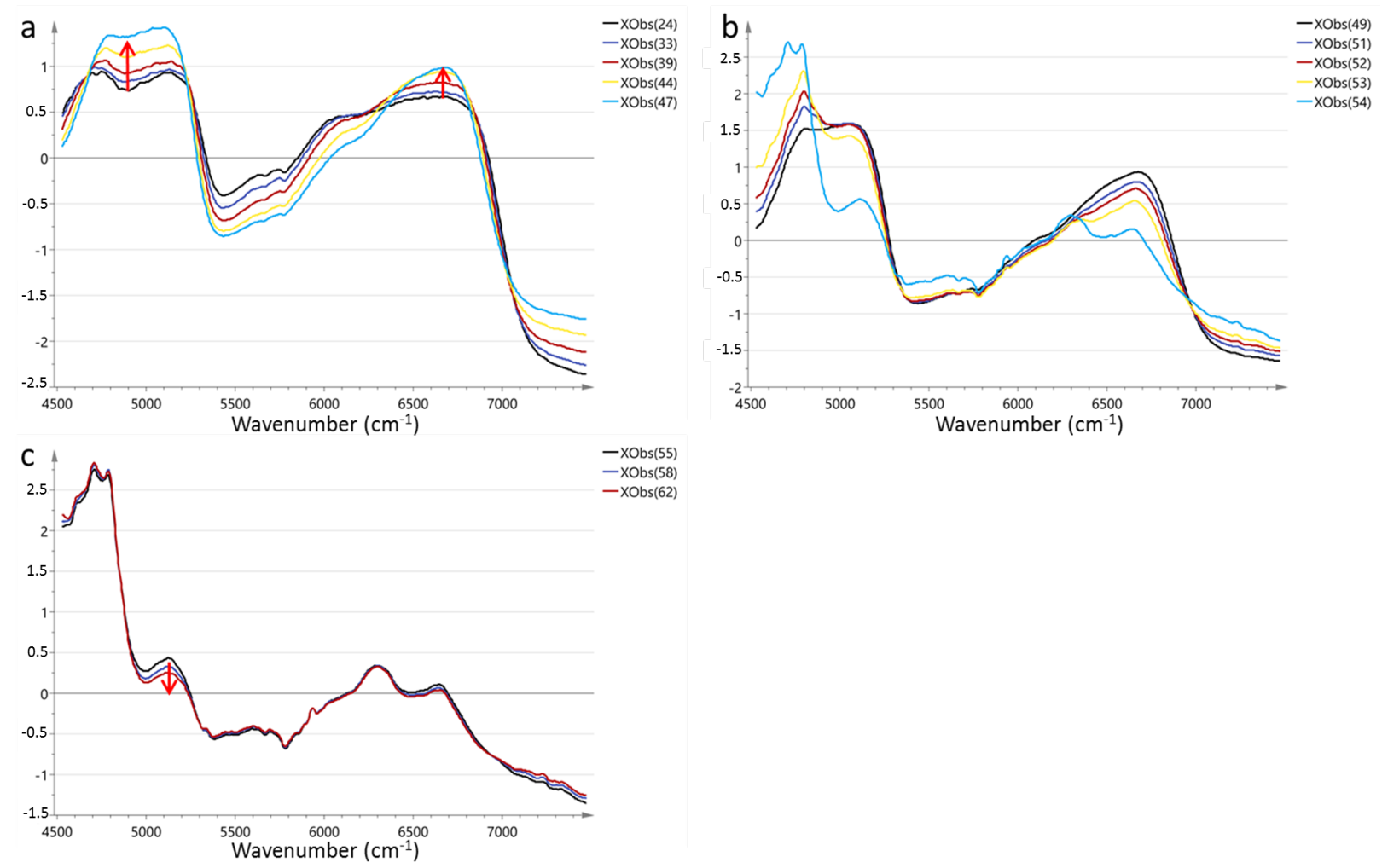

Figure 9: Visualization of the primary drying process based on in-line collected NIR spectra: [a] primary drying progress: overwhelming ice bands during first part of primary drying. [b] formulation characteristic NIR bands appear in the spectra. Primary drying ends when the last ice signal disappears. [c] secondary drying: water band at $5160 \mathrm{~cm}^{-1}$ decreases in intensity

The primary drying endpoint was determined for every verification run and the ratio between this experimental determined primary drying endpoint and the model-based primary drying endpoint (56 min $40 \mathrm{sec}$ ) was made. The results of this comparison can be found in table 3 . The mean ratio was $1.05 \pm 0.07$, indicating a good agreement between the experimental and computed primary drying time.

The small mismatch between the experimental and model based primary drying endpoints could be explained by (i) at the NIR monitoring site, a hole in the electric heating pad is created leading to a possible different energy transfer at that location (ii) some assumptions and simplifications were introduced in the mechanistic model $\left(P_{w, c}\right.$ assumed to be equal to $P_{c}, 30 \%$ safety factor for choked flow (see section 3.1.)) (iii) some input parameters in the model are estimations or experimentally determined values associated with an error (e.g. $K_{v}, T_{g}^{\prime}$ )

All six verification runs resulted in a freeze-dried product with an elegant cake aspect without any visual signs of cake collapse (Figure 10 .

\section{General conclusion and future perspectives}

The developed mechanistic model allows calculating the optimal dynamic heating pad temperature during primary drying of spin frozen formulation in vials. Experimental data revealed that $K_{v}$ is independent of the chamber pressure. Based on in-line NIR monitoring, the endpoint of primary drying for the verification experiments was determined and compared to the model predicted primary drying endpoint. These verification experiments showed a good agreement between both endpoints (1.05 \pm 0.07$)$. The visual aspect of the 
Table 3: Relation between the experimental primary drying time and the model based primary drying time (56min 40sec) for the different validation runs

\begin{tabular}{ccc} 
Experiment & $\begin{array}{c}\text { Experimental primary } \\
\text { drying time (min) }\end{array}$ & $\begin{array}{c}\text { Ratio experimental vs model } \\
\text { based primary drying time }(-)\end{array}$ \\
\hline 1 & 64 & 1.13 \\
2 & 55 & 0.97 \\
3 & 62 & 1.09 \\
4 & 59 & 1.04 \\
5 & 54 & 0.95 \\
6 & 62 & 1.09 \\
& & \\
&
\end{tabular}

Figure 10: Visual aspect of the freeze-dried formulation obtained with the settings of the validation run

freeze-dried formulation was good without any visual signs of macroscopic cake collapse. An uncertainty analysis will be conducted in the future to explore the influence of the estimated input variables and process parameters on the model output. Similar to this research, Van Bockstal et al. described the development of a mechanistic model to determine the dynamic infra-red heater temperature during primary drying in a continuous freeze-drying process [15. The results of the uncertainty analysis on that mechanistic model will be compared to the results of the uncertainty analysis of the mechanistic model developed in this paper.

\section{Nomenclature}

\section{References}

[1] C. FDA, 2016 Novel Drugs Summary (January 2017).

[2] E. Y. Chi, S. Krishnan, T. W. Randolph, J. F. Carpenter, Physical stability of proteins in aqueous solution: Mechanism and driving forces in nonnative protein aggregation, Pharmaceutical Research 20.

[3] H. Costantino, M. Pikal, Lyophilization of biopharmaceuticals, 2004.

[4] L. De Meyer, P. J. Van Bockstal, J. Corver, C. Vervaet, J. P. Remon, T. De Beer, Evaluation of spin freezing versus conventional freezing as part of a continuous pharmaceutical freeze-drying concept for unit doses, International Journal of Pharmaceutics 496 .

[5] W. Wang, Lyophilisation and development of solid pharmaceuticals, Vol. 203, 2000.

[6] M. J. Pikal, S. Shah, D. Senior, J. E. Lang, Physical chemistry of freeze-drying: measurement of sublimation rates for frozen aqueous solutions by a microbalance technique, Journal of pharmaceutical sciences 72 .

[7] L. Rey, J. C. May, Freeze Drying / Lyophilization of Pharmaceutical and Biological Products, Vol. 206, 2010.

[8] T. Jennings, Lyophilization : introduction and basic principles, Vol. 25, 1999.

[9] J. K. Kasper, W. Friess, The freezing step in lyophilization: Physico-chemical fundamentals, freezing methods and consequences on process performance and quality attributes of biopharmaceuticals, European Journal of Pharmaceutics and Biopharmaceutics 78.

[10] M. J. Pikal, Freeze drying, Encyclopedia of Pharmaceutical Technology, Third Edition.

[11] M. C. Sarragua, T. De Beer, C. Vervaet, J. P. Remon, J. A. Lopes, A batch modelling approach to monitor a freeze-drying process using in-line Raman spectroscopy, Talanta 83. 


\begin{tabular}{|c|c|}
\hline$\Delta H_{s}$ & latent heat of ice sublimation $(2838 \mathrm{~J} / \mathrm{g})$ \\
\hline$\Delta l$ & increase in dry product layer per time step $\mathrm{t}(\mathrm{m})$ \\
\hline$\Delta t$ & time step to calculate $\mathrm{l}(\mathrm{h})$ \\
\hline$\dot{m}_{s u b}$ & sublimation rate $(\mathrm{kg} / \mathrm{h})$ \\
\hline$\alpha$ & parameter describing $K_{v}$ in function of $P_{c}$ \\
\hline$\beta$ & parameter describing $K_{v}$ in function of $P_{c}$ \\
\hline$\gamma$ & adiabatic constant for triatomic gas (-) \\
\hline$\phi$ & volume fraction of ice $(-)$ \\
\hline$\rho_{i c e}$ & density of ice $\left(\mathrm{kg} / \mathrm{m}^{3}\right)$ \\
\hline$A_{p}$ & product area available for sublimation $\left(m^{2}\right)$ \\
\hline$A_{R p}$ & constant describing $R_{p}$ in function of $l(1 / \mathrm{s})$ \\
\hline$B_{R p}$ & constant describing $R_{p}$ in function of $l(1 / \mathrm{m})$ \\
\hline$c$ & speed of sound for an ideal gas $(\mathrm{m} / \mathrm{s})$ \\
\hline$d_{v, o}$ & diameter of the vial opening (m) \\
\hline$h_{f}$ & height of the spin frozen product $(\mathrm{m})$ \\
\hline$K_{v}$ & heat transfer coefficient $\left(\mathrm{J} / \mathrm{m}^{2} \mathrm{~s} \mathrm{~K}\right)$ \\
\hline$M$ & molecular weight of water $(0.018015 \mathrm{~kg} / \mathrm{mol}$ \\
\hline$P_{c}$ & chamber pressure $(\mathrm{Pa})$ \\
\hline$P_{\text {sub }}$ & power required for ice sublimation $(\mathrm{W})$ \\
\hline$P_{w, c}$ & partial water vapour pressure in the drying chamber $(\mathrm{Pa})$ \\
\hline$P_{w, i}$ & vapour pressure at the sublimation front $(\mathrm{Pa})$ \\
\hline$R$ & gas constant $(8.3144621 \mathrm{~J} /(\mathrm{mol} \mathrm{K}))$ \\
\hline$R_{p}$ & dry product mass transfer resistance $(\mathrm{m} / \mathrm{s})$ \\
\hline$R_{p, 0}$ & constant describing $R_{p}$ in function of $l(\mathrm{~m} / \mathrm{s})$ \\
\hline$r_{p, i}$ & radius from the center of the vial to the border of the spin frozen layer $(\mathrm{m})$ \\
\hline$r_{v, i}$ & inner radius of the glass vial $(\mathrm{m})$ \\
\hline$T_{c}$ & collapse temperature $(\mathrm{K})$ \\
\hline$T_{e u}$ & eutectic temperature (K) \\
\hline$T_{g}^{\prime}$ & glass transition temperature of the maximum freeze-concentrated formulation $(\mathrm{K})$ \\
\hline$T_{h}^{g}$ & heating pad temperature $(\mathrm{K})$ \\
\hline$T_{i}$ & product temperature at sublimation front $(\mathrm{K})$ \\
\hline$T_{p}$ & product temperature $(\mathrm{K})$ \\
\hline$T_{w v}$ & temperature of water vapour $(\mathrm{K})$ \\
\hline$V$ & filling volume $\left(\mathrm{m}^{3}\right)$ \\
\hline$V_{\max }$ & maximum volume of sublimed gas \\
\hline$v_{\text {sound,safe }}$ & safe velocity of sound $(\mathrm{m} / \mathrm{s})$ \\
\hline$\dot{m}_{\max }$ & maximum sublimation rate $(\mathrm{kg} / \mathrm{s})$ \\
\hline
\end{tabular}

[12] A. Kauppinen, M. Toiviainen, O. Korhonen, J. Aaltonen, J. Paaso, M. Juuti, J. Ketolainen, In-Line Multipoint NearInfrared Spectroscopy for Moisture Content Quanti ficationduring Freeze-Drying, Analytical Chemistry 85.

[13] J. Corver, Method and system for freeze-drying injectable compositions, in particular pharmaceutical. (2013).

[14] P.-J. Van Bockstal, L. De Meyer, J. Corver, C. Vervaet, T. De Beer, Noncontact Infrared-Mediated Heat Transfer During Continuous Freeze-Drying of Unit Doses, Journal of Pharmaceutical Sciences.

[15] P. J. Van Bockstal, Mechanistic modelling of infrared mediated energy transfer during the primary drying step of continuous freeze-drying process, European Journal of Pharmaceutics and Biopharmaceutics 114.

[16] V. R. Koganti, E. Y. Shalaev, M. R. Berry, T. Osterberg, M. Youssef, D. N. Hiebert, F. a. Kanka, M. Nolan, R. Barrett, G. Scalzo, G. Fitzpatrick, N. Fitzgibbon, S. Luthra, L. Zhang, Investigation of design space for freeze-drying: use of modeling for primary drying segment of a freeze-drying cycle., AAPS PharmSciTech 12.

[17] S. T. F. C. Mortier, P. J. Van Bockstal, J. Corver, I. Nopens, K. V. Gernaey, T. De Beer, Uncertainty analysis as essential step in the establishment of the dynamic Design Space of primary drying during freeze-drying, European Journal of Pharmaceutics and Biopharmaceutics 103.

[18] A. K. Konstantinidis, W. Kuu, L. Otten, S. L. Nail, R. R. Sever, Controlled nucleation in freeze-drying: effects on pore size in the dried product layer, mass transfer resistance, and primary drying rate, Journal of pharmaceutical sciences 100.

[19] D. Fissore, R. Pisano, A. A. Barresi, Advanced approach to build a design space for the primary drying of a pharmaceutical 
freeze-drying process, International Journal of Drug Development and Research 100 (11) (2011) 4922-4933.

[20] D. Fissore, R. Pisano, S. Velardi, A. Barresi, M. Galan, PAT tools for the optimization of the freeze-drying process, Pharmaceutical Engineering 29.

[21] M. Kochs, C. Körber, I. Heschel, B. Nunner, The influence of the freezing process on vapour transport during sublimation in vacuum-freeze-drying of macroscopic samples, International Journal of Heat and Mass Transfer 36.

[22] J. A. Searles, J. F. Carpenter, T. W. Randolph, The ice nucleation temperature determines the primary drying rate of lyophilization for samples frozen on a temperature-controlled shelf, Journal of Pharmaceutical Sciences 90.

[23] A. Hottot, S. Vessot, J. Andrieu, Freeze drying of pharmaceuticals in vials: Influence of freezing protocol and sample configuration on ice morphology and freeze-dried cake texture, Chemical Engineering and Processing: Process Intensification 46

[24] D. E. Overcashier, T. W. Patapoff, C. C. Hsu, Lyophilization of protein formulations in vials: Investigation of the relationship between resistance to vapor flow during primary drying and small-scale product collapse, Journal of Pharmaceutical Sciences 88

[25] S. M. Patel, T. Doen, M. J. Pikal, Determination of end point of primary drying in freeze-drying process control, AAPS PharmSciTech 11.

[26] R. Pisano, D. Fissore, A. A. Barresi, I. Chimica, P. Torino, Heat Transfer in Freeze-Drying Apparatus.

[27] M. Pikal, Use of laboratory data in freeze drying process design: heat and mass transfer coefficients and the computer simulation of freeze drying, Journal of parenteral science and technology 39.

[28] W. Y. Kuu, L. M. Hardwick, M. J. Akers, Rapid determination of dry layer mass transfer resistance for various pharmaceutical formulations during primary drying using product temperature profiles, International Journal of Pharmaceutics 313.

[29] J. Vercruysse, M. Toiviainen, M. Fonteyne, N. Helkimo, J. Ketolainen, M. Juuti, U. Delaet, I. van Assche, J. Remon, C. Vervaet, T. De Beer, Visualization and understanding of the granulation liquid mixing and distribution during continuous twin screw granulation using NIR chemical imaging, European Journal of Pharmaceutics and Biopharmaceutics 86 .

[30] T. De Beer, P. Vercruysse, A. Burggraeve, T. Quinten, J. Ouyang, X. Zhang, C. Vervaet, J. P. Remon, W. R. G. Baeyens, In-line and real-time process monitoring of a freeze-drying process using raman and NIR spectroscopy as complementary process analytical technology (PAT) tools, Journal of Pharmaceutical Sciences 98.

[31] S. Pieters, T. De Beer, J. C. Kasper, D. Boulpaep, O. Waszkiewicz, M. Goodarzi, C. Tistaert, W. Friess, J. P. Remon, C. Vervaet, Y. Vander Heyden, Near-infrared spectroscopy for in-line monitoring of protein unfolding and its interactions with lyoprotectants during freeze-drying, Analytical Chemistry 84 